\title{
New Approach to Predict Shear Capacity of Reinforced Concrete Beams
}

\section{Strengthened with NSM Technique}

Hadi Baghi, Joaquim A.O. Barros

\begin{abstract}
Understanding the shear behavior of a concrete beam is still a challenging task due to several complex mechanisms it involves. The modified compression field theory (MCFT) demonstrated to be able of predicting with good accuracy the shear capacity of reinforced concrete (RC) members. Due to its iterative nature, the MCFT is not a straightforward design methodology, and a simplified MCFT (SMCFT) approach of this method was proposed to overcome this aspect. This model takes into account the tensile stress installed in the cracked concrete, and inclination of the diagonal compressive strut, and requires a smaller number of model parameters than MCFT.

This paper presents a new approach to predict the shear capacity of RC beams shear strengthened with fiber reinforced polymer (FRP) laminates/rods applied according to the near surface mounted (NSM) technique. The new approach is based on the SMCFT and considers the relevant features of the interaction between NSM FRP systems and surrounding concrete like debonding of FRP laminate/rod and fracture of surrounding concrete of FRP. The experimental results of 100 beams strengthened with different configurations and shear strengthening ratio of FRP reinforcements are used to appraise the predictive performance of the developed approach. By evaluating the ratio between the experimental results to the analytical predictions $\left(V_{\text {exp. }} / \mathrm{V}_{\text {ana. }}\right)$, an average value 1.09 is obtained for the developed approach with a coefficient of variation of $11 \%$.
\end{abstract}

Keywords: Simplified Modified Compression Field Theory; Reinforced concrete beams; Shear failure; Shear strengthening; Near Surface Mounted technique; Carbon fiber reinforced polymers. 
21 (MCFT).

22 Truss model was explained by Ritter (1899) and Mörsch (1908) ${ }^{2}$, which is based on the following 23

\section{Introduction}

two assumptions: 1) the diagonal compression struts, before and after cracking of the cross section, 
1 are inclined at an angle of 45 degrees to the longitudinal axis of the RC member; 2) the concrete

2 tensile strength is negligible ${ }^{2}$. Hence, the truss model predicts conservative values for the ultimate

3 shear strength of the RC elements since smaller inclinations can occur (crossing larger number of

4 stirrups), and concrete post-cracking tensile strength can be significant.

5 The Modified Compression Field Theory (MCFT) was developed by Vecchio and Collins ${ }^{3}$ by

6 taking into account the resisting contribution of cracked RC member in tension. By applying this

7 theory for the prediction of the shear strength of 102 panels tested experimentally, an average

8 predictive level of 1.01 (ratio between experimental and model results), with a coefficient of

9 variation $(\mathrm{COV})$ of $12.2 \%$, was obtained ${ }^{4}$. Nevertheless, solving the equations of the MCFT

10 requires an iterative procedure and the knowledge of a relatively high number of parameters, which

11 introduces extra difficulties in the designer perspective.

12 Bentz et al. ${ }^{4}$ suggested a simplified approach of the MCFT method. In this model, the shear

13 strength of a section is a function of two parameters: the tensile stress factor in the cracked concrete

$14(\beta)$, and the inclination of the diagonal compressive stress in the web of the section $(\theta)$. In spite

15 of the simple format of the equations for $\beta$ and $\theta$, the method provides excellent predictions of

16 shear strength of RC beams. In the simplified MCFT (SMCFT), the average ratio of experimental

17 to predicted shear strength for $102 \mathrm{RC}$ elements was 1.11 with a COV of $13.0 \%{ }^{4}$.

18 Shear failure of RC elements due to design deficiency is brittle, and several strengthening

19 techniques are being proposed to avoid this type of rupture, such as the near surface mounted

20 (NSM). In this technique, carbon fiber reinforced polymer (CFRP) laminates/rods are inserted into

21 grooves open on the concrete cover, and bonded to the surrounding substrata by using an

22 appropriate adhesive. Research has shown that a significant increase in the shear resistance of RC

23 beams is reachable by using the NSM CFRP technique ${ }^{5,6}$. 
1 Nanni et al. ${ }^{7}$ and Bianco et al. ${ }^{8}$ are two amongst the most consistent models proposed to predict the shear strength contribution of the NSM CFRP laminate/rod in RC beams. In the Nanni et al. model the inclination of the critical diagonal crack (CDC) with respect to the axis of the beam $(\theta$

4 ) was assumed constant and equal to 45 degrees, which limits the predictive performance of this model. One of the input parameters in Bianco et al. approach is the inclination of the CDC.

6 However, due to lack of an appropriate approach to predict the $\theta$, this model gives conservative estimates of the shear strength contribution of the NSM laminate/rod. In fact, when applied to an experimental program formed by $72 \mathrm{RC}$ beams, the average ratio of the prediction versus the experimental value was 0.69 with a COV of $42 \%^{8}$.

10 In the present paper a model based on the Simplified MCFT and Bianco et al. formulation is 11 proposed (herein abbreviated by BSMCFT) to predict the shear capacity of RC beams shear 12 strengthened according to the NSM technique. In the first part of this paper, the SMCFT and the

13 Bianco et al. are briefly introduced. To appraise the predictive performance of the developed 14 approach, it is applied on the prediction of the shear capacity of beams shear strengthened with the 15 NSM technique and tested experimentally.

\section{Research Significance}

17 An analytical model is developed to predict shear strength of reinforced concrete beams 18 strengthened with the Near Surface Mounted (NSM) FRP laminate/rod. This model integrates the relevant features of the Simplified Modified Compression Field Theory (SMCFT) and the key mechanisms provided by FRP reinforcements applied according to the NSM technique for the

21 shear strengthening of RC beams, namely: 1) debonding of FRP reinforcements; 2) fracture of concrete surrounding FRPs; 3) tensile rupture of FRP reinforcements; 4) inclination of the shear crack. The results of 100 beams with and without existing shear reinforcement and with and 
without CFRP laminates are summarized, and the predictive performance of the new design approach is appraised, having been obtained an average of 1.09 with a COV of $11 \%$.

\section{Simplified Modified Compression Field Theory}

In 1929 Wanger developed the Tension Field Theory (TFT) in analogy to the post-buckling shear resistance of thin-webbed metal girder ${ }^{9}$. In this theory it was assumed that after the thin-webbed girder buckled, it had no resistance to compression, and the shear was carried out by diagonal tension. It was also assumed that the inclination of the diagonal tensile stresses coincided with the inclination of the principal tensile strains ${ }^{9}$. Vecchio and Collins ${ }^{3}$ applied the TFT to the RC members by assuming that, after cracking, the concrete carried no tension, and the shear was carried out by a field of diagonal compressive stresses. Since the Compression Field Theory (CFT) neglects the resisting contribution of cracked concrete in tension, conservative estimates of shear strength were predicted. The Modified Compression Field Theory (MCFT) is an enhancement of the CFT, since it takes into account the resisting contribution of the cracked concrete in tension ${ }^{3}$. Vecchio and Collins ${ }^{3}$ studied the relationship between diagonal compressive stress and diagonal compressive strain, and authors found that principal compressive stress was not only function of the principal compressive strain but also principal stresses and strains have almost the same orientation. They also verified that after formation of diagonal cracking, tensile stresses still exist in the concrete between cracks. Combined with shear stresses on the crack faces, these tensile stresses increased the ability of the cracked RC concrete to resist shear. However, due to huge amount of variables and assumptions, solving the equations of the MCFT is cumbersome if done by hand ${ }^{10}$.

Bentz et al. ${ }^{4}$ suggested a simplified approach of the MCFT method, where the shear strength of a section is a function of two parameters: the tensile stress factor in the cracked concrete $(\beta)$, and 
1 the inclination of the diagonal compressive stress in the web of the section $(\theta)$. For elements

2 without transverse reinforcement the $\beta$ value, depends on longitudinal strain $\left(\varepsilon_{x}\right)$ and crack

3 spacing parameter $\left(s_{x e}\right)$. The $\theta$ and $\beta$ are the results of the multiplication of $\varepsilon_{x}$ and $s_{x e}$, the first

4 one $\left(\varepsilon_{x}\right)$ simulating the "strain effect" and the second $\left(s_{x e}\right)$ the "size effect".

5 These two effects are not really independent, but for the simplified calculation of the SMCFT this

6 interdependence is ignored. The equations 1 and 2 were suggested to calculate $\theta$ and $\beta$,

7 respectively.

$$
\begin{aligned}
& \theta=\left(29+7000 \varepsilon_{\mathrm{x}}\right) \cdot\left(0.88+\frac{\mathrm{s}_{\mathrm{xe}}}{2500}\right) \leq 75^{\circ} \\
& \beta=\frac{0.4}{1+1500 \varepsilon_{x}} \cdot \frac{1300}{1000+s_{x e}}
\end{aligned}
$$

8 These two equations are to be used with concrete strength units in MPa and $s_{x e}$ in $\mathrm{mm}$. If in.-lb

9 units are used the 2500 in equation 1 becomes 100, 1300 in equation 2 becomes 51 , and the 1000

10 becomes 39. For concrete strength in psi, the 0.4 in equation 2 becomes 4.8 .

$11 s_{x e}$ can be determined by equation 3 :

$$
s_{x e}=\frac{35 s_{x}}{a_{g}+16} \geq 0.85 s_{x}
$$

12 where $s_{x}$ and $a_{g}$ are the vertical distance between longitudinal reinforcement and maximum

13 dimension of aggregates, respectively, both in $\mathrm{mm}$. If in.-lb units are being used, the 35 and 16 in

14 equation 3 should be replaced by 1.38 and 0.63 , respectively ${ }^{4}$.

15 If the longitudinal reinforcement is not yielded, equation 4 can be used to calculate the $\varepsilon_{x}$ :

$$
\varepsilon_{x}=\frac{f_{s x}}{E_{s}}=\frac{v \cdot \cot \theta-v_{c} / \cot \theta}{E_{s} \rho_{s x}}
$$


1 where $E_{s}, \rho_{s x}, v_{c}$ and $v$ are the modulus of elasticity of longitudinal reinforcement, longitudinal

2 steel reinforcement percentage, shear stress in concrete, and shear stress of a RC member, 3 respectively. In Simplified MCFT, the shear strength of a RC beam can be determined as follows

4 (equation 5):

$$
v=v_{c}+v_{s}=\beta \sqrt{f_{c}^{\prime}}+\rho_{y} f_{\text {yyield }} \cot \theta
$$

5 where $v_{s}=\rho_{y} f_{\text {yyield }} \cot \theta$ is the shear strength provided by steel stirrups. In equation $5 f_{c}^{\prime}$ is the

6 concrete compressive strength, while $\rho_{y}$ and $f_{y \text { yield }}$ are the ratio, and the yield stress of the

7 transverse steel reinforcement, respectively. More information about MCFT and SMCFT can be

8 found in Baghi ${ }^{10}$.

\section{Model for the evaluation of the shear strength contribution of NSM}

\section{laminate/rod}

Bianco et al. ${ }^{11}$ proposed a 3D mechanical model to predict the shear strength contribution of NSM CFRP laminates/rods. The mode of failure of an NSM FRP laminate/rod subjected to an imposed end slip can be categorized into four groups: debonding, tensile rupture of laminate, concrete semicone tensile fracture, and a mixed shallow semi-cone plus debonding failure mode (Fig. 2d). Recently the same authors proposed a simplified version of this model ${ }^{8}$ by introducing the following simplifications:

1. The local bond stress-slip relationship $\tau(\delta)$ can be modeled by a bi-linear diagram instead of a multi linear diagram.

2. Concrete fracture surface is assumed a semi-pyramid instead of a semi-cone. 
3. Attention can be focused on the average-available-bond-length NSM FRP laminates/rods glued on the relevant prism of surrounding concrete instead of local bond between NSM FRP laminates/rods embedded in concrete cover.

4. Determining the constitutive law of the average-available-bond-length of the NSM FRP laminates/rods instead of constitutive laws of local bond between NSM FRP laminates/rods and surrounding concrete.

During the loading process of a RC beam, when the concrete average tensile strength is attained at the bottom part of the web, some shear cracks originate, and successively progress towards the flange of the beam. These cracks can generate a single crack, Critical Diagonal Crack (CDC), with inclination of $\theta$ with respect to the beam longitudinal axis (Fig. 2a). At load step $t_{1}$, the two web parts become separated by the CDC and they start moving apart by rotating around the crack tip (point E in Fig. 2a). From that step, by increasing the applied load, the CDC opening angle $\gamma\left(t_{n}\right)$ progressively widens. The laminates that bridge the CDC offer resistance to its widening. The load imposed to the laminate, in consequence of the loaded end slip $\left(\delta_{L i}\right)$ evolution, is transferred by bond to the concrete surrounding the laminate along its effective bond length, $L_{f i}$ which is the shorter length between the two parts into which the crack divides its actual length.

There are two other assumptions that simplify the original formulation proposed by Bianco et al.: The concrete fracture can be accounted to determine the equivalent value of the average resisting bond length $\bar{L}_{R f i}^{e q}$. The equivalent value of the average resisting bond length is the portion of the available average resisting bond length, $\bar{L}_{R f i}^{e q}=\eta \bar{L}_{R f i}$.

The post peak behavior of the bond based constitutive law $V_{f i}^{b d}\left(\bar{L}_{R f i}^{e q} ; \delta_{L i}\right)$ of the equivalent value of the average resisting bond length can be ignored. 
1 The following paragraphs introduce the formulation of this approach:

2 Step 1: Input parameters data includes: beam cross section $\left(h_{w}, b_{w}\right)$; inclination of CDC and NSM

3 FRP laminates $\left(\theta, \theta_{f}\right)$; horizontal spacing of NSM FRP laminates $s_{f}$; angle $\alpha$ between axis and

4 principal surfaces that generate the semi-pyramidal fracture surface; Young's modulus and tensile

5 strength of FRP $\left(E_{f}, f_{f u}\right)$; concrete average compressive strength $\left(f_{c}^{\prime}\right)$; thickness and width of

6 the NSM FRP laminates $\left(a_{f}, b_{f}\right)$; the value of the bond strength and ultimate slip $\left(\tau_{0}, \delta_{1}\right)$ (these

7 values are assumed $20.1 \mathrm{MPa}[2.9 \mathrm{ksi}]$ and $7.12 \mathrm{~mm}$ [0.28 in], respectively $\left.{ }^{11}\right)$.

8 Step 2: Determining the average available resisting bond length and the minimum integer number

9 of FRP laminates/rods that cross the CDC (Fig. 2a):

$$
\begin{aligned}
& \bar{L}_{R f i}=\frac{h_{w} \cdot \sin \theta \cdot\left(\cot \theta+\cot \theta_{f}\right)}{4 \cdot \sin \left(\theta+\theta_{f}\right)} \\
& N_{f, \text { int }}^{l}=\text { round }\left[h_{w} \cdot \frac{\cot \theta+\cot \theta_{f}}{s_{f}}\right]
\end{aligned}
$$

10 Step 3: Evaluation of geometric constants (equation 8), mechanical constants (equation 9), and 11 bond modeling constants (equation 10) (Fig. 2c):

$$
\begin{aligned}
& L_{p}=2 b_{f}+a_{f} ; A_{c}=s_{f} \frac{b_{w}}{2} ; L_{d}=\frac{h_{w}}{\sin \theta} \\
& V_{f}^{t r}=a_{f} \cdot b_{f} \cdot f_{f u} \\
& f_{c t m}=0.3\left(f_{c}^{\prime}-8\right)^{2 / 3} \\
& E_{c}=2.2 \times 10^{4}\left(\frac{f_{c}^{\prime}}{10}\right)^{1 / 3}
\end{aligned}
$$
and $2.2 \times 10^{4}$ and 10 in equation $9 \mathrm{c}$ become 3191 and 1.45 , respectively. 


$$
J_{1}=\frac{L_{p}}{A_{f}}\left[\frac{1}{E_{f}}+\frac{A_{f}}{A_{c} E_{c}}\right] ; C_{3}=\frac{V_{f}^{t r} \cdot J_{1}}{L_{p} \cdot \lambda} ; \frac{1}{\lambda^{2}}=\frac{\delta_{1}}{\tau_{b} J_{1}} ; L_{R f e}=\frac{\pi}{2 \lambda} ; V_{f 1}^{b d}=\frac{L_{p} \lambda \delta_{1}}{J_{1}}
$$

1 Step 4: Reduction factor of the initial average available resisting bond length $(\eta)$, and equivalent

2 value of the average resisting bond length $\left(\bar{L}_{R f i}^{e q}\right)($ Fig. 3a):

The average resistance bond length is determined from:

$$
\bar{L}_{R f i}^{e q}=\eta \cdot \bar{L}_{R f i}
$$

where:

$$
\eta=\left\{\begin{array}{l}
\frac{f_{c t m}}{f_{c t m}^{*}} \quad \text { if } f_{c t m}<f_{c t m}^{*} \\
1 \quad \text { if } f_{c t m} \geq f_{c t m}^{*}
\end{array}\right.
$$

$$
L_{R f i}=\left\{\begin{array}{lll}
\bar{L}_{R f i} & \text { if } & \bar{L}_{R f i} \leq L_{R f e} \\
L_{R f e} & \text { if } & \bar{L}_{R f i}>L_{R f e}
\end{array}\right.
$$

9 Step 5: Determine the value of imposed slip in correspondence of which the comprehensive peak

10 force transmissible by $\bar{L}_{R f i}^{e q}$ is attained $\left(V_{f i}\left(\bar{L}_{R f i}^{e q} ; \delta_{L i}\right)\right)(\mathbf{F i g} . \mathbf{3 c})$ :

$$
\delta_{L u}=\left\{\begin{array}{lll}
\delta_{L 1}\left(\bar{L}_{R f i}^{e q}\right) & \text { if } & V_{f 1}^{d b}<V_{f}^{t r} \\
\min \left[\delta_{L 1}\left(\bar{L}_{R f i}^{e q}\right) ; \delta_{L i}\left(V_{f}^{t r}\right)\right] & \text { if } & V_{f 1}^{d b} \geq V_{f}^{t r}
\end{array}\right.
$$


where $\delta_{L 1}\left(\bar{L}_{R f i}^{e q}\right)$ is the value of imposed end slip in correspondence of which the bondbased constitutive law $V_{f i}^{b d}\left(\bar{L}_{R f i}^{e q} ; \delta_{L i}\right)$ attains the peak value (Fig. 3b):

$$
\delta_{L 1}\left(\bar{L}_{R f i}^{e q}\right)=\left\{\begin{array}{lll}
\delta_{1}\left[1-\cos \left(\lambda \bar{L}_{R f i}^{e q}\right)\right] & \text { if } & \bar{L}_{R f i}^{e q} \leq L_{R f e} \\
\delta_{1} & \text { if } & \bar{L}_{R f i}^{e q}>L_{R f e}
\end{array}\right.
$$

and $\delta_{L i}\left(V_{f}^{t r}\right)$ is the imposed end slip in correspondence of which the strip tensile strength is attained:

$$
\delta_{L i}\left(V_{f}^{t r}\right)=\delta_{1}\left\{1-\cos \left[-\arcsin \frac{C_{3}}{\delta_{1}}\right]\right\}
$$

Step 6: Maximum effective capacity $V_{f i, e f f}^{\max }$ of the FRP laminate/rod with equivalent average resisting bond length $\bar{L}_{R f i}^{e q}($ Fig. 3c):

The $V_{f i, f f}^{\max }$ is evaluated by neglecting the post peak behavior of the equivalent average resisting bond length (Fig. $\mathbf{3 b}$ and $\mathbf{3 c}$ ), whose complete physical meaning is described elsewhere ${ }^{8}$.

$$
V_{f i, e f f}^{\max }=\frac{\delta_{1} A_{2}}{2 L_{d} A_{3} \gamma_{\max }}\left[\frac{\pi}{2}-\arcsin \psi-\psi \sqrt{1-\psi^{2}}\right]
$$

where:

$$
A_{2}=\frac{L_{p} \lambda}{J_{1}} ; A_{3}=\frac{\sin \left(\theta_{f}+\theta\right)}{2 \delta_{1}} ; \gamma_{\max }=\frac{2 \delta_{L u}}{L_{d} \sin \left(\theta_{f}+\theta\right)} ; \psi=1-A_{3} \cdot \gamma_{\max } \cdot L_{d}
$$

Step 7: Shear strength contribution provided by a system of NSM CFRP laminate/rod:

$$
V_{f d}=2 \cdot N_{f, \text { int }}^{l} \cdot V_{f i, e f f}^{\max } \cdot \sin \theta_{f}
$$


2 Based on ACI design code ${ }^{12}$, shear strength of a RC beam strengthened with FRP (herein

3 abbreviated by NACI) can be determined by:

$$
V=V_{c}+V_{s}+V_{f}
$$

where $V_{c}, V_{s}$, and $V_{f}$ are the shear strength provided by concrete, steel stirrups and FRP, respectively. The contribution of concrete and steel stirrups is obtained by the following respective

6 equations:

$$
\begin{aligned}
& V_{c}=0.17 \sqrt{f_{c}^{\prime}} b_{w} d \\
& V_{s}=\frac{A_{s y} f_{\text {yyield }}}{s} d
\end{aligned}
$$

7 while the contribution of FRP is determined according to the Nanni et al. ${ }^{7}$ model, whose detailed description is provided elsewhere ${ }^{7,13}$. In this model the inclination of the CDC with respect to the axis of the beam is assumed $45^{\circ}$, and conservative values of the shear strength contribution of FRP

\section{Strengthened with NSM Technique}

14 Adapting the simplified MCFT to the NSM technique is performed by adding formulation of NSM technique, suggested by Bianco et al. ${ }^{8}$, to simplified MCFT. As mentioned in the previous section, one of the input parameters in Bianco et al. approach is inclination of the CDC with respect to the

17 longitudinal axis of the beam. To evaluate this parameter, the equation 1 provided by SMCFT can 18 be used in Bianco et al. formulation. 
1 The new formulation for shear strength, based on SMCFT, combined with Bianco et al. approach

2 can be expressed as:

$$
v=v_{c}+v_{s}+v_{f d}=\beta \sqrt{f_{c}^{\prime}}+\rho_{y} f_{\text {yield }} \cot \theta+2 \cdot N_{f, \text { int }}^{l} \cdot V_{f i, e f f}^{\max } \cdot \frac{\sin \theta_{f}}{b_{w} d}
$$

where $\theta$ and $\beta$ are obtained from equations 1 and 2 , respectively, while the longitudinal strain is calculated from equation 4.

5 The solution procedure to calculate the shear strength of the concrete beams, according to the BSMCFT, is obtained applying the following procedure (Fig. 4):

7 Step 1: Input parameters;

8 Step 2: Assume a value for $\varepsilon_{x}$;

$9 \quad$ Step 3: Calculate the crack spacing using equation 3;

10 Step 4: Calculate $\theta$ and $\beta$ using equation 1 and equation 2, respectively;

11 Step 5: Calculate the shear strength based on equation 24;

12 Step 6: Calculate the longitudinal strain, $\varepsilon_{x}$, according to equation 4 and compare to $\varepsilon_{x}$ of step 1.

13 Return to Step 2 with $\varepsilon_{x}$ that has been calculated in Step 5 until $\left|\varepsilon_{x}^{q+1}-\varepsilon_{x}^{q}\right| / \varepsilon_{y \text { yield }} \leq 10^{-6}$;

\section{Performance of the proposed formulation for predicting the shear capacity of RC Beams shear strengthened with NSM systems}

Table 1 summarizes experimental results available in the literature in terms of RC beams shear strengthened with NSM reinforcement ${ }^{5,6,10,13-20}$. These experimental programs include beams of different size, different longitudinal and transverse steel reinforcement ratios, and different NSM CFRP types and strengthening ratios.

The beams tested by Dias and Barros ${ }^{5,13-16}$ were of type $\mathrm{T}$ cross section with the same shear span to effective depth ratio (2.5), CFRP laminates, and epoxy adhesive. These beams differed on the 
1 amount of existing still stirrups ( $\rho_{s y}=0.1 \%$ and $0.17 \%$ ), percentage of longitudinal reinforcement

$2 \quad\left(\rho_{s x}=2.8 \%\right.$ and $\left.3.2 \%\right)$, and concrete compressive strength $\left(f_{c}^{\prime}=18.6,39.7\right.$, and $31.1 \mathrm{MPa}[2.7$,

35.8 , and $4.5 \mathrm{ksi}]$ ). These series were strengthened with different configurations of NSM strips in

4 terms of both inclination $\theta_{f}$ and spacing $s_{f}$. However, the series V and VI of these authors ${ }^{15}$

5 were formed by beams of a higher shear aspect ratio (3.3) and concrete average compressive

$6 \quad$ strength $\left(f_{c}^{\prime}=59.4 \mathrm{MPa}[8.6 \mathrm{ksi}]\right)$.

7 Those beams were characterized by the following common geometric and mechanical parameters:

$8 b_{w}=180 \mathrm{~mm}(7.1 \mathrm{in}) ; h_{w}=300 \mathrm{~mm}(11.8 \mathrm{in}) ; f_{f u}=2952 \mathrm{MPa}(428 \mathrm{ksi})$ (for the series I, II, III,

$9 \mathrm{IV}$ ) and $f_{f u}=2848 \mathrm{MPa}\left(413 \mathrm{ksi}\right.$ ) (for the series V and VI); $E_{f}=166.6 \mathrm{GP}$ (24.2 Msi) (for the

10 series IV), $E_{f}=174.3 \mathrm{GPa}(25.3 \mathrm{Msi})$ (for the series III, V, and VI), and $E_{f}=170.9 \mathrm{GPa}(24.8$

11 Msi) (for series I and II); $a_{f}=1.4 \mathrm{~mm}(0.05 \mathrm{in}) ; b_{f}=9.5 \mathrm{~mm}(0.37 \mathrm{in})$ (for the series I, II, III, V

12 and IV) and $a_{f}=1.4 \mathrm{~mm}(0.05 \mathrm{in}) ; b_{f}=10 \mathrm{~mm}(0.39 \mathrm{in})$ (for series IV).

13 The beams tested by Chaallal et al. ${ }^{17}$ were of $\mathrm{T}$ cross section type, and were strengthened in shear

14 by CFRP rods, and tested under three point bending. These beams were characterized by cross-

15 section dimensions of $b_{w}=152 \mathrm{~mm}(6.0 \mathrm{in})$ and $h_{w}=304 \mathrm{~mm}(12.0 \mathrm{in})$. Concrete had average

16 compressive strength of $25 \mathrm{MPa}(3.6 \mathrm{ksi})$ and $35 \mathrm{MPa}(5.1 \mathrm{ksi})$ in the series I and II, respectively.

17 CFRP rods of $9.5 \mathrm{~mm}$ (0.37 in) diameter, with tensile strength of $f_{f u}=1270 \mathrm{MPa}(184 \mathrm{ksi})$ and

18 modulus of elasticity of $E_{f}=148 \mathrm{GPa}(21.5 \mathrm{Msi})$, were used.

19 The beams tested by De Lorenzis and Nanni ${ }^{6}$ were T cross section type and strengthened in shear with CFRP rods, and tested under four point bending. These beams were characterized by cross-

21 section dimensions of $b_{w}=150 \mathrm{~mm}(5.9 \mathrm{in})$ and $h_{w}=305 \mathrm{~mm}(12 \mathrm{in})$. The concrete had an average 
1 compressive strength of $31 \mathrm{MPa}(4.5 \mathrm{ksi})$. CFRP rods of nominal diameter around $9.5 \mathrm{~mm}(0.37$ in), with tensile strength $f_{f u}=1875 \mathrm{MPa}(271.9 \mathrm{ksi})$ and modulus of elasticity $E_{f}=104.8 \mathrm{GPa}$

3 (15.2 Msi), were adopted. Two different percentages of steel stirrups were used ( $\rho_{s y}=0.0 \%$ and $4 \quad 0.26 \%)$.

5 The beams tested by Rizzo and De Lorenzis ${ }^{18}$ were of rectangular cross-section type, strengthened 6 in shear by either rods (NR) or laminates (NL), and tested under four point bending. These beams 7 were characterized by cross-section dimensions of $b_{w}=200 \mathrm{~mm}(7.9 \mathrm{in})$ and $h_{w}=210 \mathrm{~mm}(8.3$ in). The concrete had an average compressive strength of $29.3 \mathrm{MPa}$ (4.2 ksi). Round CFRP rods of $8 \mathrm{~mm}(0.31 \mathrm{in})$ diameter, with tensile strength $f_{f u}=2210 \mathrm{MPa}(87 \mathrm{ksi})$ and modulus of elasticity $E_{f}=145.7 \mathrm{GPa}(21.1 \mathrm{Msi})$, were used. The laminates had cross-section dimensions $a_{f}=2.0 \mathrm{~mm}$

11 (0.07 in) and $b_{f}=16.0 \mathrm{~mm}(0.63 \mathrm{in})$, and mechanical properties of $f_{f u}=2070 \mathrm{MPa}(300 \mathrm{ksi})$ and $E_{f}=121.5 \mathrm{GPa}(17.6 \mathrm{Msi})$.

13 The beams tested by Islam ${ }^{19}$ were of rectangular cross-section type, strengthened in shear with 14 CFRP round rods and tested under four point bending. These beams were characterized by crosssection dimensions of $b_{w}=254 \mathrm{~mm}(10 \mathrm{in})$ and $h_{w}=305 \mathrm{~mm}$ (12 in). The concrete had an average compressive strength of $49.75 \mathrm{MPa}(4.3 \mathrm{ksi})$. Round CFRP rods of $9 \mathrm{~mm}$ (0.35 in) diameter, with

17 tensile strength $f_{f u}=2070 \mathrm{MPa}(300 \mathrm{ksi})$ and modulus of elasticity $E_{f}=124 \mathrm{GPa}(17.9 \mathrm{Msi})$, 18 were used.

19 The beams tested by Baghi ${ }^{10}$ were $\mathrm{T}$ cross-section type and tested under three point bending. $\mathrm{T}$ 20 cross section beams had a cross section dimensions of $b_{w}=180 \mathrm{~mm}(7.1 \mathrm{in})$ and $h_{w}=400 \mathrm{~mm}$ 21 (11.8 in). The length of monitored shear span, $a$, was 2.5 times the effective beam's depth. The 22 concrete had an average compressive strength of $32.7 \mathrm{MPa}$ (4.74 ksi). CFRP laminates of $a_{f}=1.4$ 
1 (0.05 in) $\mathrm{mm} ; b_{f}=10 \mathrm{~mm}$ (0.39 in), with tensile strength $f_{f u}=2620 \mathrm{MPa}(380 \mathrm{ksi})$ and modulus

2 of elasticity $E_{f}=150 \mathrm{GPa}(21.8 \mathrm{Msi})$, were used.

3 The RC beams tested by Cisneros et al. ${ }^{20}$ were of rectangular cross-section strengthened in shear

4 by either bars (their label starts by B) or laminates (their label starts by S) and tested under three

5 point bending. The cross-section dimensions of the beams were $b_{w}=200 \mathrm{~mm}$ and $h_{w}=350 \mathrm{~mm}$.

6 Concrete average compressive strength ranged from $f_{c}^{\prime}=22.84 \mathrm{MPa}(3.3 \mathrm{ksi})$ to $f_{c}^{\prime}=29.11 \mathrm{MPa}$

7 (4.2 ksi). The NSM FRP bars were characterized by $8 \mathrm{~mm}$ diameter ( $0.31 \mathrm{in})$, while the laminates

8 had cross section dimensions of $a_{f}=2.5 \mathrm{~mm}(0.1 \mathrm{in})$ and $b_{f}=15 \mathrm{~mm}$ (0.59 in). FRP mechanical

9 properties were $f_{f u}=2500 \mathrm{MPa}(363 \mathrm{ksi})$ and $E_{f}=165 \mathrm{GPa}(23.9 \mathrm{Msi})$.

10 The angle $\alpha$ for BSMCFT was assumed to be equal to $28.5^{\circ}$ for all the experimental programs ${ }^{8}$.

11 To define the local bond stress-slip relationship (Fig. 2b) the following values were assumed: $\tau_{0}=$

$12 \quad 20.1 \mathrm{MPa}(2.9 \mathrm{ksi}) ; \delta_{1}=7.12 \mathrm{~mm}(0.28 \mathrm{in})^{8}$.

13 In NACI, to define average bond stress $\left(\tau_{b}\right)$ and effective strain $\left(\varepsilon_{f e}\right)$ the following values were

14 assumed: $\tau_{b}=16.1 \mathrm{MPa}(2.3 \mathrm{ksi})$ and $\varepsilon_{f e}=0.59 \%$ for the CFRP laminates ${ }^{13}$, and $\tau_{b}=6.9 \mathrm{MPa}(1$

$15 \mathrm{ksi}$ ) and $\varepsilon_{f e}=0.4 \%$ for the CFRP rods ${ }^{7}$.

16 When CFRP rods were used, the equivalent square cross-section was adopted in the calculations.

17 The maximum dimension of aggregates $\left(a_{g}\right)$ was assumed $25 \mathrm{~mm}(0.98 \mathrm{in})$ for all the experimental

18 programs, since this information was not available in the majority of the original publications.

19 Fig. 5a shows the ratio between experimental results and analytical predictions from the BSMCFT

20 formulation and NACI $\left(\lambda=V_{\text {exp. }} / \mathrm{V}_{\text {ana }}\right)$. The prediction of the results based on NACI are very

21 high. The ratio between experiments and predictions is in average 1.47 with COV of $22 \%$. For 
1 SMCFT approach the average $V_{\text {exp. }} / \mathrm{V}_{\text {ana. }}$ ratio is 1.09 with COV of $11 \%$, which shows a better

2 prediction than NACI approach.

3 A systematic trend in the error can be highlighted if the results are plotted in non-dimensional

4 form, as it is shown in Fig. $\mathbf{5 b}$, where the shear resistance is normalized by a force dimensional

5 parameter $b_{w} d f_{c}^{\prime}$. In this figure, two lines limiting to $\pm 25 \%$ the deviation of the predicted values

6 from the experimental values are also represented, and it is easy to see that most of the results of

7 NACI formulation are outside of these bounds, however it verified that almost all of the results of

$8 \quad$ BSMCFT model are inside of these bounds.

9 The values of $\lambda$ are also classified according to the modified version of the Demerit Points 10 Classification (DPC) ${ }^{21}$ proposed by Collins ${ }^{22}$, where a penalty (PEN) is assigned to each range

11 of $\lambda$ parameter according to Table 2, and total of penalties (Total PEN) determines the performance

12 of each analytical approach.

13 According to the results in Table 2 and Fig. 5a, the predictive performance of BSMCFT model is

14 better than NACI, since BSMCFT model has a large number of predictions in the appropriate

15 safety interval according to the DPC (Table 2), $\lambda \in[0.85-1.15[: 60$ samples with the BSMCFT

16 and 13 samples with the NACI. According to results presented in Table 2, 80 and 36 samples are

17 in the conservative interval ( $\lambda \in[1.15-2[$ ), when using NACI and BSMCFT model, respectively.

18 Both models have predictions on the unsafe interval (Table 2), $(\lambda \in[0.5-0.85[): 4$ samples with

19 BSMCFT and 3 samples with NACI. The NACI also has predictions on the extremely conservative 20 interval $(\lambda \geq 2): 4$ samples. 
1 Based on the data presented in Fig. 5 and Table 1 and 2 it can be concluded that the new approach

2 predicts with high accuracy the shear strength of RC beams strengthened with CFRP

3 laminates/rods applied according to the NSM technique.

\section{Conclusion}

5 To predict the shear resistance of the reinforced concrete (RC) beams shear strengthened according

6 to the NSM technique, an analytical approach was, and its predictive performance was assessed

7 by considering results available in literature.

8 The new approach is based on the simplified modified compression field theory (SMCFT), which

9 takes into account the tensile stress factor in cracked concrete $(\beta)$, and inclination of diagonal

10 compressive strut $(\theta)$. For estimating the contribution of the CFRP laminates Bianco et al.

11 formulations was selected. The experimental results of 100 beams with different configurations

12 and percentage of CFRP laminates/rods were used to appraise the predictive performance of the

13 developed approach. The new approach considers the inclination of the critical diagonal crack to

14 determine the minimum number of FRP laminates/rods that cross the shear crack. By evaluating

15 the ratio between the experimental results and the analytical predictions, an average value of 1.09

16 with a COV of $11 \%$ was obtained. Based on the results, it can be concluded that the new approach

17 predicts with high accuracy the shear strength of RC beams shear strengthened with CFRP

18 laminates/rods.

\section{ACKNOWLEDGMENTS}

20 The study presented in this paper is a part of the research project 38780, QREN, titled "CutInov -

21 Innovative carbon fibre reinforced polymer laminates with capacity for a simultaneous flexural

22 and shear/punching strengthening of reinforced concrete elements", co-financed by the European 
1 Regional Development Fund (FEDER) through the Operational Program COMPETE. The first

2 author acknowledges the research grant provided by this project.

\section{Notation}

$A_{f} \quad$ Area of the strip's cross section

$A_{2} \quad$ Integration constant entering the expressions to evaluate the $V_{f i, e f f}^{\max }$

$A_{3} \quad$ Integration constant entering the expressions to evaluate the $V_{f i, \text { fff }}^{\max }$

$C_{3} \quad$ Integration constant for the softening friction phase

$J_{1} \quad$ Bond modeling constant

$L_{d} \quad$ CDC length

$L_{p} \quad$ Effective perimeter of the strip cross section

$L_{\text {Rfe }} \quad$ Effective resisting bond length

$L_{R f i} \quad i^{t h}$ strip resisting bond length

$\bar{L}_{R f i}^{e q} \quad$ Equivalent average resisting bond length

$\bar{L}_{R f i} \quad$ Average available resisting bond length

$N_{f, \text { int }}^{l} \quad$ Equivalent average resisting bond length

$V_{f}^{t r} \quad$ Strip tensile rupture capacity

$V_{f d} \quad$ Design value of the NSM shear strengthening contribution

$V_{f i, e f f}^{\max } \quad$ Maximum effective capacity

$V_{f 1}^{b d} \quad$ Maximum value of force transferable through bond by the given FRP NSM system

$f_{c t m}^{*} \quad$ Value of concrete average tensile strength for values larger than which concrete fracture does not occur 
$f_{c t m} \quad$ Concrete average tensile strength

$s_{x e} \quad$ Effective longitudinal crack spacing

$\alpha \quad$ Angle defining the concrete fracture surface

$\beta \quad$ Factor accounting for the tensile stress in the cracked concrete

$\delta_{1} \quad$ Slip corresponding to the end of softening friction

$\delta_{L i} \quad$ Imposed slip at the loaded extremity of the $i^{\text {th }}$ strip

Imposed slip in correspondence of which the comprehensive peak force
$\delta_{L u} \quad$ transmissible by $\bar{L}_{R f i}^{e q}$ is attained

$\delta_{L 1} \quad$ Value of $\delta_{L i}$ defining the end of the first phase of the bond-based constitutive law

$\varepsilon_{x} \quad$ Longitudinal strain

$\varepsilon_{\text {y yeild }} \quad$ Yield strain in transverse steel reinforcement

$\gamma_{\max } \quad$ CDC opening angle for which the maximum effective capacity is attained

$\gamma_{x y} \quad$ Shear strain

$\eta \quad$ Reduction factor of the initial average available resisting bond length

$\lambda \quad$ Constant entering the governing differential equation for elastic phase

$\tau_{0} \quad$ adhesive-cohesive initial bond strength

$\psi \quad$ Constant necessary to evaluate the maximum effective capacity provided by the equivalent average resisting bond length

\section{References}

2 1. Bellamkonda, S.A., "Modeling of Shear Strengthening of Reinforced Concrete Beams Retrofitted with Externally Bonded Fiber Reinforced Polymers," Master thesis, Louisiana State University, 2013.

2. Blanksvärd, T., "Strengthening of concrete structures by the use of mineralbased composites," Luleå University of Technology, Sweden, 2009. 
$13 . \quad$ Vecchio, F.J., and Collins, M.P., "The Modified Compression-Field Theory for Reinforced

$2 \quad$ Concrete Elements Subjected to Shear." ACI Journal Proceedings, 83 (2), 1986: pp. 219-

3

4 231.

4. Bentz, E.C., Vecchio, F.J., and Collins, M.P., "Simplified Modified Compression Field Theory for Calculating Shear Strength of Reinforced Concrete Elements. " ACI Structural Journal, 103 (4), 2006.: pp. 614-624.

5. Dias, S.J.E., and Barros, J.A.O., "Shear strengthening of RC T-section beams with low concrete using NSM CFRP laminates." Journal Cement \& Concrete Composites, 2011. 3(2): pp. 334-345.

6. De Lorenzis, L., and Nanni, A., "Shear Strengthening of Reinforced Concrete Beams with Near-Surface Mounted Fiber-Reinforced Polymer Rods." ACI Structural Journal, 98 (1), 2001: pp. 60-68.

7. Nanni, A., Di Ludovico, M., and Parretti, R., "Shear Strengthening of a PC Bridge Girder with NSM CFRP Rectangular Bars." Advances in Structural Engineering, 7(4), 2004: pp. 97-109.

8. Bianco, V., Monti, G., and Barros, J.A.O., Design formula to evaluate the NSM FRP strips shear strength contribution to a RC beam. Composites Part B: Engineering, 56, 2014: pp. 960-971.

9. $\quad$ Sang-Yeol, P., "Prediction of Shear Strength of R/C beams using Modified Compression Field Theory and ACI Code." KCI Concrete Journal, 11(3), 1999: pp. 5-17.

10. Baghi, H., "The effectivness of SHCC-FRP panles of the shear resistance of RC beams," University of Minho, Portugal, 2015, PhD Thesis. 
1 11. Bianco, V., Monti, G., and Barros, J.A.O., "Theoretical model and computational procedure to evaluate the NSM FRP strips shear strength contribution to a RC beam." ASCE Journal of Structural Engineering, 137(11), 2011: pp. 1359-1372.

12. ACI 440.2R-08 - Guide for the Design and Construction of Externally Bonded FRP Systems for Strengthening Concrete Structures: 2008.

13. Dias, S.J.E., and Barros, J.A.O., "Performance of reinforced concrete $T$ beams strengthened in shear with NSM CFRP laminates." Engineering Structures, 32(2), 2010: pp. 373-384.

14. Dias, S.J.E., and Barros, J.A.O., "Shear strengthening of RC beams with NSM CFRP laminates: Experimental research and analytical formulation." Composite Structures, 99, 2013: pp. 477-490.

15. Dias, S.J.E., Barros, J.A.O., "Shear Strengthening of T Cross Section Reinforced Concrete Beams by Near Surface Mounted Technique." ASCE Journal of Composites for Construction, 12(3), 2008: pp. 300-311.

16. Dias, S.J.E., "Experimental and anlytical research in the shear strengthening of reinforced concreet beams using the near surface mounted technique with CFRP strips," in Department of Civil Engineering 2008, University of Minho, Guimarães-Portugal, in Portugese.

17. Chaallal, O., Mofidi, A., Benmokrane, B., and Neale, K., "Embedded Through-Section FRP Rod Method for Shear Strengthening of RC Beams: Performance and Comparison with Existing Techniques." Composites for Construction, 15(3), 2011: pp. 374-383. 
1 18. Rizzo, A., and De Lorenzis, L., "Behaviour and capacity of RC beams strengthened in shear with NSM FRP reinforcement." Construction and Building Materials, 3(4), 2009: pp. $1555-1567$.

4 19. Islam, A.A., Effective methods of using CFRP bars in shear strengthening of concrete girders. Engineering Structures, 31(3), 2009: pp. 709-714.

6 20. Cisneros, D., Arteaga, A., De Diego, A., Alzate, A., Perera, R., Experimental Study on

21. Moraes Neto, B., Barros, J., Melo, G., Model to Simulate the Contribution of Fiber

22. Collins, M.P., Evaluation of shear design procedures for concrete structures, A Report prepared for the CSA technical committee on reinforced concrete design, 2001 


\section{List of Tables:}

Table 1- Summary of experimental and analytical results

Table 2: Predictive performance of different approaches according to the modified version of the DPC 


\section{List of Figures:}

Fig. 1- Components of shear resistance for concrete beams without shear reinforcement: shear resistance in the compression zone $\left(V_{c}\right)$; interface shear transfer by aggregate interlocking in the cracked concrete $\left(V_{a}\right)$; and dowel action provided by the longitudinal reinforcement $\left(V_{d}\right)$.

Fig. 2- Schematic representation of the Bianco et al. Model ${ }^{11}$; a) average-available-bond-length NSM strip and concrete prism of influence; b) adopted local bond stress-slip relationship; c) sections of the concrete prism; d) different failure mode of an NSM FRP laminate/rod subjected to an imposed end slip.

Fig. 3- a) available length reduction factor as function of the concrete average tensile strength, $b$ ) bond-based constitutive law for NSM FRP strips with different values of resisting bond length, $c$ ) assumed comprehensive constitutive law of the equivalent average available resisting bond length strip (Bianco et al. $\left.{ }^{8}\right)(1 \mathrm{kN}=0.22 \mathrm{kip}$ and $1 \mathrm{~mm}=0.04 \mathrm{in})$.

Fig. 4- Calculation procedure of BSMCFT.

Fig. 5- a) Ratio between experimental and predicted shear resistance; b) Predicted nondimensional failure shear force of the beams, in compression with experimental values. 
Table 1- Summary of experimental and analytical results

\begin{tabular}{|c|c|c|c|c|c|c|c|c|}
\hline \multirow[b]{2}{*}{ Beam Label } & \multirow[b]{2}{*}{$\begin{array}{c}f_{c}^{\prime}(\mathrm{Mpa} \\
[\mathrm{ksi}])\end{array}$} & \multicolumn{4}{|c|}{ Reinforcement } & \multirow[b]{2}{*}{$\begin{array}{c}F_{\text {exp. }}(\mathrm{kN} \\
[\mathrm{kips}])\end{array}$} & & \\
\hline & & $\rho_{s x}$ & $\theta_{f}$ & $\frac{\rho_{y} f_{\text {y yield }}}{f_{c}^{\prime}}$ & $\frac{\rho_{f} f_{f u}}{f_{c}^{\prime}}$ & & $\frac{F_{\text {exp. }}}{F_{B S M C F T}}$ & $\frac{F_{\text {exp. }}}{F_{N A C I}}$ \\
\hline \multicolumn{9}{|c|}{ Dias and Barros 13,14} \\
\hline$C-R-I$ & \multirow{18}{*}{$\begin{array}{c}39.7 \\
(5.76)\end{array}$} & 0.028 & - & 0 & 0 & $207(46.5)$ & 1.11 & 1.78 \\
\hline $2 S-R-I$ & & 0.028 & - & 0.0143 & 0 & $304(68.3)$ & 1.18 & 1.71 \\
\hline $7 S-R-I$ & & 0.028 & - & 0.038 & 0 & $467(105)$ & 1.25 & 1.68 \\
\hline $2 S-4 L V-I$ & & 0.028 & $90^{\circ}$ & 0.0143 & 0.056 & $337(75.8)$ & 1.09 & 1.45 \\
\hline $2 S-7 L V-I$ & & 0.028 & $90^{\circ}$ & 0.0143 & 0.09 & $374(84.1)$ & 0.99 & 1.40 \\
\hline $2 S-10 L V-I$ & & 0.028 & $90^{\circ}$ & 0.0143 & 0.12 & $397(89.2)$ & 1.03 & 1.28 \\
\hline $2 S-4 L I 45-I$ & & 0.028 & $45^{\circ}$ & 0.0143 & 0.055 & $393(88.3)$ & 1.18 & 1.81 \\
\hline $2 S-7 L I 45-I$ & & 0.028 & $45^{\circ}$ & 0.0143 & 0.9 & $422(94.9)$ & 1.05 & 1.50 \\
\hline $2 S-10 L I 45-I$ & & 0.028 & $45^{\circ}$ & 0.0143 & 0.13 & $446(100.3)$ & 1.09 & 1.32 \\
\hline $2 S-4 L I 60-I$ & & 0.028 & $60^{\circ}$ & 0.0143 & 0.49 & $386(86.8)$ & 1.22 & 1.70 \\
\hline $2 S-6 L I 60-I$ & & 0.028 & $60^{\circ}$ & 0.0143 & 0.076 & $394(88.6)$ & 1.13 & 1.43 \\
\hline $2 S-9 L I 60-I$ & & 0.028 & $60^{\circ}$ & 0.0143 & 0.11 & $413(92.8)$ & 1.01 & 1.27 \\
\hline $4 S-4 L V-I I$ & & 0.028 & $90^{\circ}$ & 0.0237 & 0.055 & $424(95.3)$ & 1.19 & 1.55 \\
\hline $4 S-7 L V-I I$ & & 0.028 & $90^{\circ}$ & 0.0237 & 0.09 & $427(96.0)$ & 1.12 & 1.39 \\
\hline $4 S-4 L I 45-I I$ & & 0.028 & $45^{\circ}$ & 0.0237 & 0.055 & $442(99.4)$ & 1.17 & 1.71 \\
\hline $4 S-7 L I 45-I I$ & & 0.028 & $45^{\circ}$ & 0.0237 & 0.09 & $478(107.5)$ & 1.07 & 1.48 \\
\hline $4 S-4 L I 60-I I$ & & 0.028 & $60^{\circ}$ & 0.0237 & 0.048 & $444(99.8)$ & 1.22 & 1.66 \\
\hline $4 S-6 L I 60-I I$ & & 0.028 & $60^{\circ}$ & 0.0237 & 0.076 & $458(103.0)$ & 1.16 & 1.44 \\
\hline \multicolumn{9}{|c|}{ Dias and Barros ${ }^{5}$} \\
\hline$C-R-I I I$ & \multirow{13}{*}{$\begin{array}{c}18.6 \\
(2.70)\end{array}$} & 0.028 & - & 0 & 0 & $147(33.0)$ & 1.08 & 1.88 \\
\hline $2 S-R-I I I$ & & 0.028 & - & 0.0304 & 0 & $226(50.8)$ & 1.08 & 1.62 \\
\hline $4 S-R-I I I$ & & 0.028 & - & 0.0508 & 0 & $304(68.3)$ & 1.17 & 1.68 \\
\hline $2 S-7 L V-I I I$ & & 0.028 & $90^{\circ}$ & 0.0304 & 0.199 & $274(61.6)$ & 1.04 & 1.26 \\
\hline $2 S-4 L I 45-I I I$ & & 0.028 & $45^{\circ}$ & 0.0304 & 0.122 & $283(63.6)$ & 1.14 & 1.65 \\
\hline $2 S-7 L I 45-I I I$ & & 0.028 & $45^{\circ}$ & 0.0304 & 0.199 & $306(68.8)$ & 1.08 & 1.34 \\
\hline 2S-4LI60-III & & 0.028 & $60^{\circ}$ & 0.0304 & 0.107 & $282(63.4)$ & 1.17 & 1.56 \\
\hline 2S-6LI60-III & & 0.028 & $60^{\circ}$ & 0.0304 & 0.168 & $298(67.0)$ & 1.16 & 1.36 \\
\hline $4 S-7 L V-I I I$ & & 0.028 & $90^{\circ}$ & 0.0508 & 0.199 & $315(70.8)$ & 1.05 & 1.21 \\
\hline $4 S-4 L I 45-I I I$ & & 0.028 & $45^{\circ}$ & 0.0508 & 0.122 & $347(78.0)$ & 1.17 & 1.64 \\
\hline $4 S-7 L I 45-I I I$ & & 0.028 & $45^{\circ}$ & 0.0508 & 0.199 & $356(80.0)$ & 1.07 & 1.32 \\
\hline $4 S-4 L I 60-I I I$ & & 0.028 & $60^{\circ}$ & 0.0508 & 0.107 & $346(77.8)$ & 1.19 & 1.57 \\
\hline $4 S-6 L I 60-I I I$ & & 0.028 & $60^{\circ}$ & 0.0508 & 0.168 & $362(81.4)$ & 1.19 & 1.39 \\
\hline \multicolumn{9}{|c|}{ Dias and Barros ${ }^{15}$} \\
\hline$C-R-I V$ & \multirow{3}{*}{$\begin{array}{c}31.1 \\
(4.51)\end{array}$} & 0.029 & - & 0 & 0 & $243(54.6)$ & 1.47 & 2.38 \\
\hline $2 S-R-I V$ & & 0.029 & - & 0.0182 & 0 & $315(70.8)$ & 1.35 & 1.94 \\
\hline $6 S-R-I V$ & & 0.029 & - & 0.0303 & 0 & $410(92.2)$ & 1.27 & 1.69 \\
\hline
\end{tabular}




\begin{tabular}{|c|c|c|c|c|c|c|c|c|}
\hline \multirow[b]{2}{*}{ Beam Label } & \multirow{11}{*}{$\begin{array}{c}f_{c}^{\prime}(\mathrm{Mpa} \\
[\mathrm{ksi}])\end{array}$} & \multicolumn{4}{|c|}{ Reinforcement } & \multirow[b]{2}{*}{$\begin{array}{c}F_{\text {exp. }}(\mathrm{kN} \\
[\mathrm{kips}])\end{array}$} & \multirow[b]{2}{*}{$\frac{F_{\text {exp. }}}{F_{B S M C F T}}$} & \multirow[b]{2}{*}{$\frac{F_{\text {exp. }}}{F_{N A C I}}$} \\
\hline & & $\rho_{s x}$ & $\theta_{f}$ & $\frac{\rho_{y} f_{y \text { yield }}}{f_{c}^{\prime}}$ & $\frac{\rho_{f} f_{f u}}{f_{c}^{\prime}}$ & & & \\
\hline $2 S-3 L V-I V$ & & 0.029 & $90^{\circ}$ & 0.0182 & 0.057 & $316(71.0)$ & 1.24 & 1.95 \\
\hline $2 S-5 L V-I V$ & & 0.029 & $90^{\circ}$ & 0.0182 & 0.095 & $357(80.2)$ & 1.29 & 1.72 \\
\hline $2 S-8 L V-I V$ & & 0.029 & $90^{\circ}$ & 0.0182 & 0.152 & $396(89.0)$ & 1.25 & 1.55 \\
\hline $2 S-3 L I 45-I V$ & & 0.029 & $45^{\circ}$ & 0.0182 & 0.057 & $328(73.7)$ & 1.11 & 1.68 \\
\hline $2 S-5 L I 45-I V$ & & 0.029 & $45^{\circ}$ & 0.0182 & 0.095 & $384(86.3)$ & 1.18 & 1.68 \\
\hline $2 S-8 L I 45-I V$ & & 0.029 & $45^{\circ}$ & 0.0182 & 0.152 & $382(85.9)$ & 1.05 & 1.47 \\
\hline $2 S-3 L I 60-I V$ & & 0.029 & $60^{\circ}$ & 0.0182 & 0.057 & $374(74.1)$ & 1.45 & 1.85 \\
\hline $2 S-5 L I 60-I V$ & & 0.029 & $60^{\circ}$ & 0.0182 & 0.085 & $392(88.1)$ & 1.28 & 1.85 \\
\hline $2 S-7 L I 60-I V$ & & 0.029 & $60^{\circ}$ & 0.0182 & 0.123 & $406(91.3)$ & 1.22 & 1.68 \\
\hline \multicolumn{9}{|c|}{$\operatorname{Dias}^{16}$} \\
\hline$C-R-V$ & \multirow{13}{*}{$\begin{array}{c}59.4 \\
(8.61)\end{array}$} & 0.031 & - & 0 & 0 & $252(44.5)$ & 0.97 & 1.22 \\
\hline $3 S-R-V$ & & 0.031 & - & 0.0095 & 0 & $360(80.9)$ & 1.05 & 1.47 \\
\hline $3 S-6 L V-V$ & & 0.031 & $90^{\circ}$ & 0.0095 & 0.025 & $387(87.0)$ & 0.91 & 1.29 \\
\hline $3 S-10 L V-V$ & & 0.031 & $90^{\circ}$ & 0.0095 & 0.041 & $497(111.7)$ & 0.91 & 1.45 \\
\hline $3 S-5 L I 45-V$ & & 0.031 & $45^{\circ}$ & 0.0095 & 0.025 & $492(110.6)$ & 1.07 & 1.74 \\
\hline $3 S-9 L I 45-V$ & & 0.031 & $45^{\circ}$ & 0.0095 & 0.041 & $564(126.8)$ & 0.99 & 1.61 \\
\hline $3 S-5 L I 60-V$ & & 0.031 & $60^{\circ}$ & 0.0095 & 0.022 & $498(112.0)$ & 1.14 & 1.71 \\
\hline $3 S-8 L I 60-V$ & & 0.031 & $60^{\circ}$ & 0.0095 & 0.035 & $585(131.5)$ & 1.20 & 1.72 \\
\hline $5 S-R-V I$ & & 0.031 & - & 0.0143 & 0 & $410(92.2)$ & 1.05 & 1.46 \\
\hline $5 S-5 L I 45-V I$ & & 0.031 & $45^{\circ}$ & 0.0143 & 0.025 & $560(125.9)$ & 1.12 & 1.74 \\
\hline 5S-9LI45-VI & & 0.031 & $45^{\circ}$ & 0.0143 & 0.041 & $627(140.9)$ & 1.03 & 1.62 \\
\hline $5 S-5 L I 60-V I$ & & 0.031 & $60^{\circ}$ & 0.0143 & 0.022 & $556(125)$ & 1.16 & 1.69 \\
\hline $5 S-8 L I 60-V I$ & & 0.031 & $60^{\circ}$ & 0.0143 & 0.035 & $655(147.2)$ & 1.24 & 1.74 \\
\hline \multicolumn{9}{|c|}{ Chaallal et al. ${ }^{17}$} \\
\hline$S O-C O N-I$ & \multirow{4}{*}{$\begin{array}{c}25.0 \\
(3.62)\end{array}$} & 0.038 & - & 0 & 0 & $122(40.7)$ & 0.99 & 2.70 \\
\hline S1-CON-I & & 0.038 & - & 0.0812 & 0 & $351(78.9)$ & 1.07 & 0.99 \\
\hline SO-NSM-I & & 0.038 & $90^{\circ}$ & 0 & 0.54 & $331(74.4)$ & 1.13 & 1.70 \\
\hline S1-NSM-I & & 0.038 & $90^{\circ}$ & 0.0812 & 0.54 & $356(80.0)$ & 0.98 & 1.06 \\
\hline S3-CON-II & \multirow{2}{*}{$\begin{array}{c}35.0 \\
(5.07)\end{array}$} & 0.038 & - & 0.0386 & 0 & $295(66.3)$ & 0.98 & 1.68 \\
\hline S3-NSM-II & & 0.038 & $90^{\circ}$ & 0.0386 & 0.39 & $306(68.8)$ & 1.04 & 1.05 \\
\hline \multicolumn{9}{|c|}{ De Lorenzis and Nanni ${ }^{6}$} \\
\hline$B V$ & \multirow{7}{*}{$\begin{array}{c}31.0 \\
(4.50)\end{array}$} & 0.024 & - & 0 & 0 & $181(40.7)$ & 1.09 & 1.77 \\
\hline$B 90-7$ & & 0.024 & $90^{\circ}$ & 0 & 0.31 & $230(51.7)$ & 1.08 & 1.36 \\
\hline$B 90-5$ & & 0.024 & $90^{\circ}$ & 0 & 0.44 & $255(57.3)$ & 1.07 & 1.20 \\
\hline$B 45-7$ & & 0.024 & $45^{\circ}$ & 0 & 0.45 & $331(74.4)$ & 1.07 & 1.55 \\
\hline$B 45-5$ & & 0.024 & $45^{\circ}$ & 0 & 0.63 & $356(80.0)$ & 1.02 & 1.47 \\
\hline$B S V$ & & 0.024 & - & 0.029 & 0 & $306(68.8)$ & 1.12 & 1.02 \\
\hline$B S 90-7 A$ & & 0.024 & $90^{\circ}$ & 0.029 & 0.31 & $414(93.1)$ & 1.27 & 1.01 \\
\hline
\end{tabular}




\begin{tabular}{|c|c|c|c|c|c|c|c|c|}
\hline \multirow[b]{2}{*}{ Beam Label } & \multirow[b]{2}{*}{$\begin{array}{c}f_{c}^{\prime}(\mathrm{Mpa} \\
[\mathrm{ksi}])\end{array}$} & \multicolumn{4}{|c|}{ Reinforcement } & \multirow[b]{2}{*}{$\begin{array}{c}F_{\text {exp. }}(\mathrm{kN} \\
[\mathrm{kips}])\end{array}$} & & \\
\hline & & $\rho_{s x}$ & $\theta_{f}$ & $\frac{\rho_{y} f_{y \text { yield }}}{f_{c}^{\prime}}$ & $\frac{\rho_{f} f_{f u}}{f_{c}^{\prime}}$ & & $\frac{F_{\text {exp. }}}{F_{B S M C F T}}$ & $\frac{F_{\text {exp. }}}{F_{N A C I}}$ \\
\hline \multicolumn{9}{|c|}{ Rizzo and De Lorenzis 18} \\
\hline$C$ & \multirow{7}{*}{$\begin{array}{c}29.3 \\
(4.25)\end{array}$} & 0.044 & - & 0.0401 & 0 & $244(54.8)$ & 1.04 & 1.68 \\
\hline NR90-73-b & & 0.044 & $90^{\circ}$ & 0.0401 & 0.5191 & $297(66.8)$ & 1.04 & 1.42 \\
\hline$N R 90-45-b$ & & 0.044 & $90^{\circ}$ & 0.0401 & 0.8421 & $305(68.6)$ & 0.99 & 1.32 \\
\hline$N R 45-146-a$ & & 0.044 & $45^{\circ}$ & 0.0401 & 0.3671 & $326(73.3)$ & 1.11 & 1.70 \\
\hline$N R 45-73-a$ & & 0.044 & $45^{\circ}$ & 0.0401 & 0.7341 & $300(67.4)$ & 0.94 & 1.33 \\
\hline$N L 90-73-a$ & & 0.044 & $90^{\circ}$ & 0.0401 & 0.3097 & $345(77.6)$ & 1.20 & 1.22 \\
\hline$N L 45-146-a$ & & 0.044 & $45^{\circ}$ & 0.0401 & 0.219 & $310(69.7)$ & 1.06 & 1.21 \\
\hline \multicolumn{9}{|c|}{ Islam ${ }^{19}$} \\
\hline Beam1 & \multirow{4}{*}{$\begin{array}{l}49.75 \\
(7.20)\end{array}$} & 0.017 & - & 0.0338 & 0 & $365(82.1)$ & 0.86 & 0.91 \\
\hline Beam2 & & 0.017 & $90^{\circ}$ & 0.0338 & 0.1404 & $454(102)$ & 0.93 & 0.93 \\
\hline Beam3 & & 0.017 & $90^{\circ}$ & 0.0169 & 0.1404 & $427(96.0)$ & 1.09 & 1.66 \\
\hline Beam4 & & 0.017 & $90^{\circ}$ & 0.0008 & 0.1404 & $436(98.0)$ & 1.28 & 1.37 \\
\hline \multicolumn{9}{|c|}{ Baghi $^{10}$} \\
\hline$C-R$ & \multirow{3}{*}{$\begin{array}{c}33 \\
(4.77)\end{array}$} & 0.028 & - & 0 & 0 & $214(48.1)$ & 1.15 & 2.03 \\
\hline $7 S-R$ & & 0.028 & - & 0.046 & 0 & $530(119.1)$ & 1.15 & 1.78 \\
\hline$N S M-3 L 45$ & & 0.028 & $45^{\circ}$ & 0 & 0.064 & $291(65.4)$ & 1.14 & 2.15 \\
\hline \multicolumn{9}{|c|}{ Cisneros et al. ${ }^{20}$} \\
\hline Control & $27.9(4)$ & & - & 0.015 & 0 & $113(25.4)$ & 0.78 & 1.40 \\
\hline$B 90-6 a$ & $26.7(3.8)$ & & $90^{\circ}$ & 0.016 & 0.41 & $170(38.2)$ & 1.05 & 1.16 \\
\hline$B 90-6 b$ & $24.1(3.5)$ & & $90^{\circ}$ & 0.017 & 0.45 & $163(36.6)$ & 1.06 & 1.14 \\
\hline$B 90-3 a$ & $22.8(3.3)$ & & $90^{\circ}$ & 0.018 & 0.24 & $117(26.3)$ & 0.84 & 1.14 \\
\hline$B 90-3 b$ & $26.0(3.8)$ & & $90^{\circ}$ & 0.016 & 0.21 & $117(26.3)$ & 0.79 & 1.10 \\
\hline$B 45-6 a$ & $23.0(3.3)$ & & $45^{\circ}$ & 0.018 & 0.67 & $180(40.5)$ & 1.08 & 1.17 \\
\hline$B 45-6 b$ & $28.5(4.1)$ & & $45^{\circ}$ & 0.015 & 0.54 & $212(47.7)$ & 1.15 & 1.33 \\
\hline$B 45-3 a$ & $29.1(4.2)$ & & $45^{\circ}$ & 0.015 & 0.26 & $189(42.5)$ & 1.06 & 1.43 \\
\hline$B 45-3 b$ & $23.9(3.5)$ & & $45^{\circ}$ & 0.018 & 0.32 & $155(34.8)$ & 0.95 & 1.22 \\
\hline $590-6 a$ & $26.7(3.9)$ & & $90^{\circ}$ & 0.015 & 0.30 & $189(42.5)$ & 1.17 & 0.95 \\
\hline$S 90-6 b$ & $24.1(3.5)$ & & $90^{\circ}$ & 0.017 & 0.34 & $147(33.0)$ & 0.95 & 0.75 \\
\hline$S 90-3 a$ & $22.8(3.3)$ & & $90^{\circ}$ & 0.018 & 0.18 & $117(26.3)$ & 0.84 & 0.97 \\
\hline$S 90-3 b$ & $26.0(3.8)$ & & $90^{\circ}$ & 0.016 & 0.16 & $131(29.5)$ & 0.89 & 1.06 \\
\hline$S 45-6 a$ & $23.0(3.3)$ & & $45^{\circ}$ & 0.018 & 0.50 & $183(41.1)$ & 1.09 & 0.66 \\
\hline$S 45-6 b$ & $28.5(4.1)$ & & $45^{\circ}$ & 0.014 & 0.40 & $221(49.7)$ & 1.19 & 0.79 \\
\hline$S 45-3 a$ & $29.1(4.2)$ & & $45^{\circ}$ & 0.014 & 0.20 & $206(46.3)$ & 1.16 & 1.15 \\
\hline$S 45-3 b$ & $23.9(3.5)$ & & $45^{\circ}$ & 0.017 & 0.24 & $173(38.9)$ & 1.06 & 0.99 \\
\hline & & & & & & Average & 1.09 & 1.47 \\
\hline & & & & & & $\mathrm{COV}$ & $11 \%$ & $22 \%$ \\
\hline
\end{tabular}


Table 2: Predictive performance of different approaches according to the modified version of the

\begin{tabular}{|c|c|c|c|c|c|c|}
\hline \multirow[b]{2}{*}{$\lambda=V_{\text {exp. }} / \mathrm{V}_{\text {ana. }}$} & \multirow[t]{2}{*}{ classification } & \multirow[b]{2}{*}{ Penalty } & \multicolumn{2}{|c|}{$B S M C F T$} & \multicolumn{2}{|c|}{$N A C I$} \\
\hline & & & $\begin{array}{c}N^{o} \\
\text { samples }\end{array}$ & Total & $\begin{array}{c}N^{o} \\
\text { samples }\end{array}$ & Total \\
\hline$<0.5$ & Extremely Unsafe & 10 & 0 & 0 & 0 & 0 \\
\hline$[0.5-0.85[$ & Unsafe & 5 & 4 & 20 & 3 & 15 \\
\hline$[0.85-1.15[$ & Appropriate Safety & 0 & 60 & 0 & 13 & 0 \\
\hline$[1.15-2[$ & Conservative & 1 & 36 & 36 & 80 & 80 \\
\hline$\geq 2.0$ & $\begin{array}{c}\text { Extremely } \\
\text { Conservative }\end{array}$ & 2 & 0 & 0 & 4 & 8 \\
\hline$\sum P E N$ & & & 100 & 56 & 100 & 103 \\
\hline
\end{tabular}




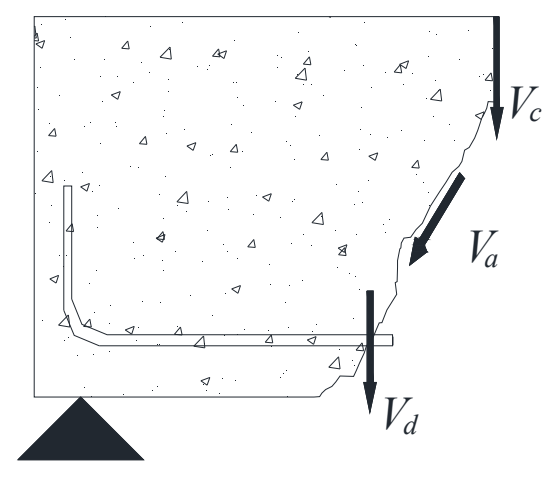

Fig. 1- Components of shear resistance for concrete beams without shear reinforcement: shear resistance in the compression zone $\left(V_{c}\right)$; interface shear transfer by aggregate interlocking in the cracked concrete $\left(V_{a}\right)$; and dowel action provided by the longitudinal reinforcement $\left(V_{d}\right)$. 


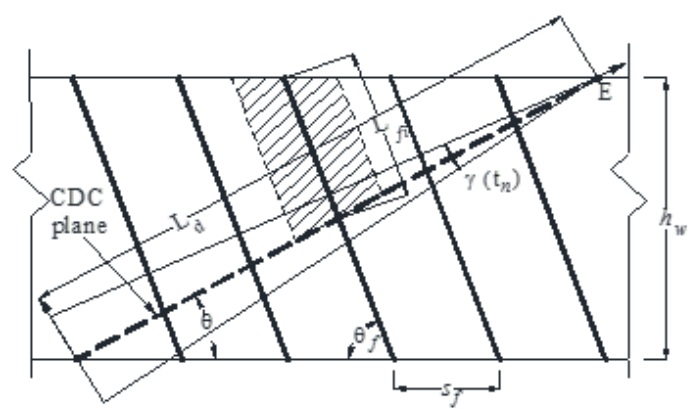

a)

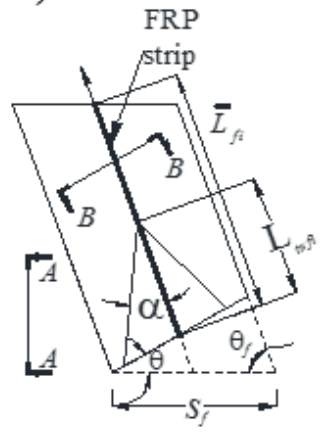

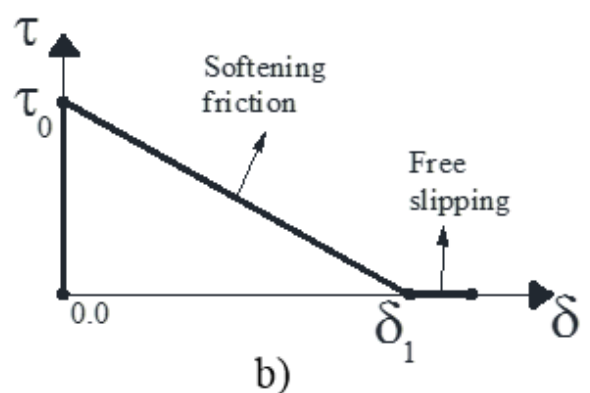

b)

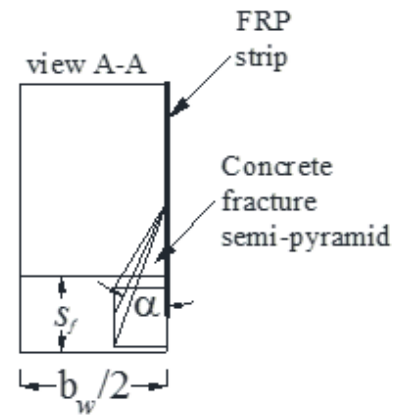

c)

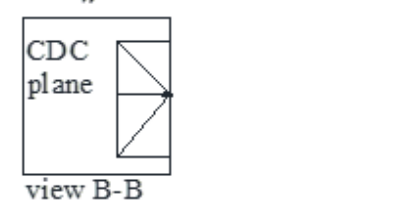

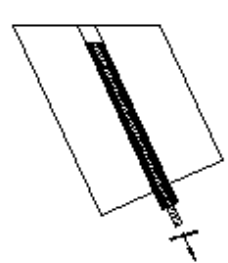

Debonding

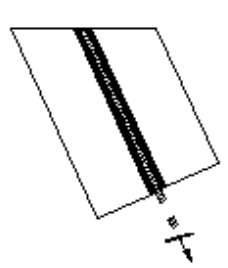

Strip ten sile rupture

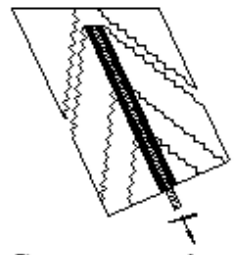

Concrete semipyramidal fracture

d)

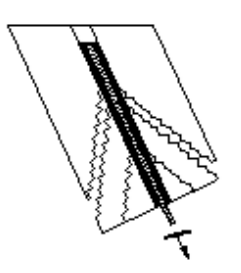

Mixed shallow -
semi-pyramid-plus semi-pyramid-p
debonding

Fig. 2- Schematic representation of the Bianco et al. Model ${ }^{11}$; a) average-available-bond-length NSM strip and concrete prism of influence; b) adopted local bond stress-slip relationship; c) sections of the concrete prism; d) different failure mode of an NSM FRP laminate/rod subjected to an imposed end slip. 


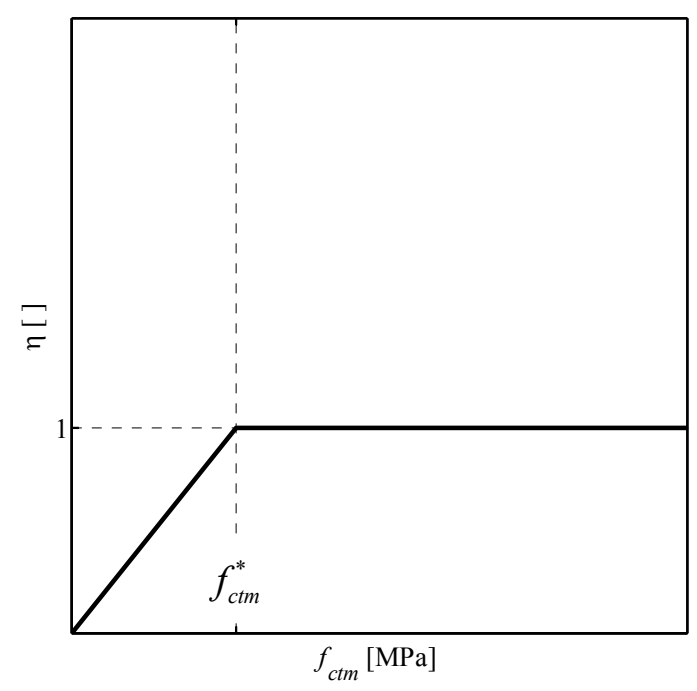

a)

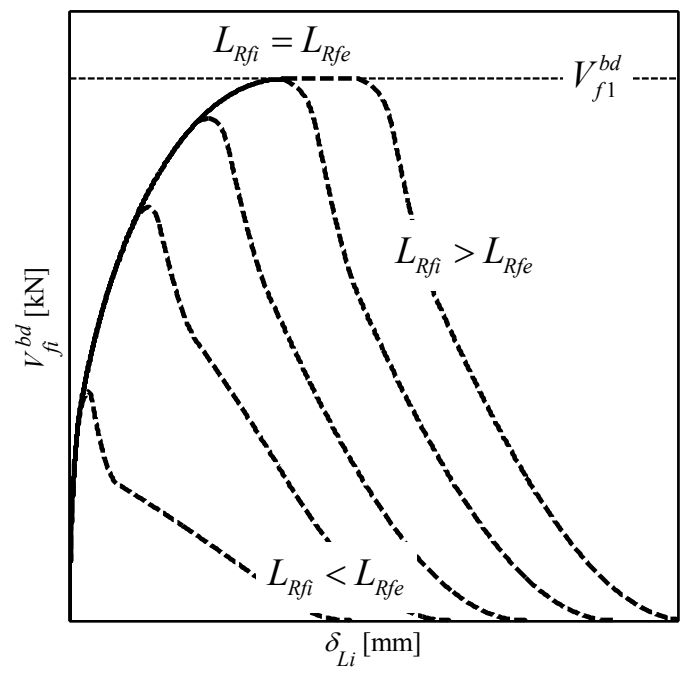

b)

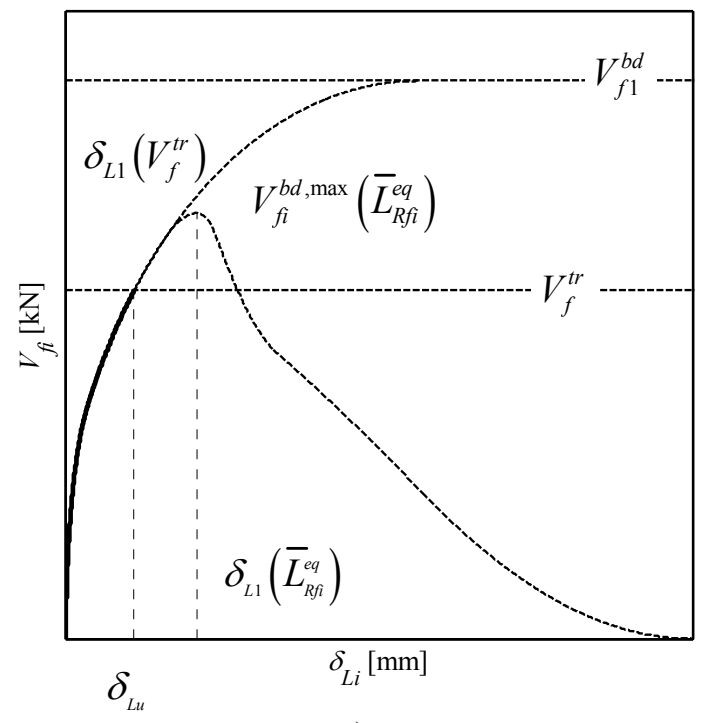

c)

Fig. 3- a) available length reduction factor as function of the concrete average tensile strength, b) bond-based constitutive law for NSM FRP strips with different values of resisting bond length, c) assumed comprehensive constitutive law of the equivalent average available resisting bond length strip (Bianco et al. $\left.{ }^{8}\right)(1 \mathrm{kN}=0.22 \mathrm{kip}$ and $1 \mathrm{~mm}=0.04 \mathrm{in}$ ). 


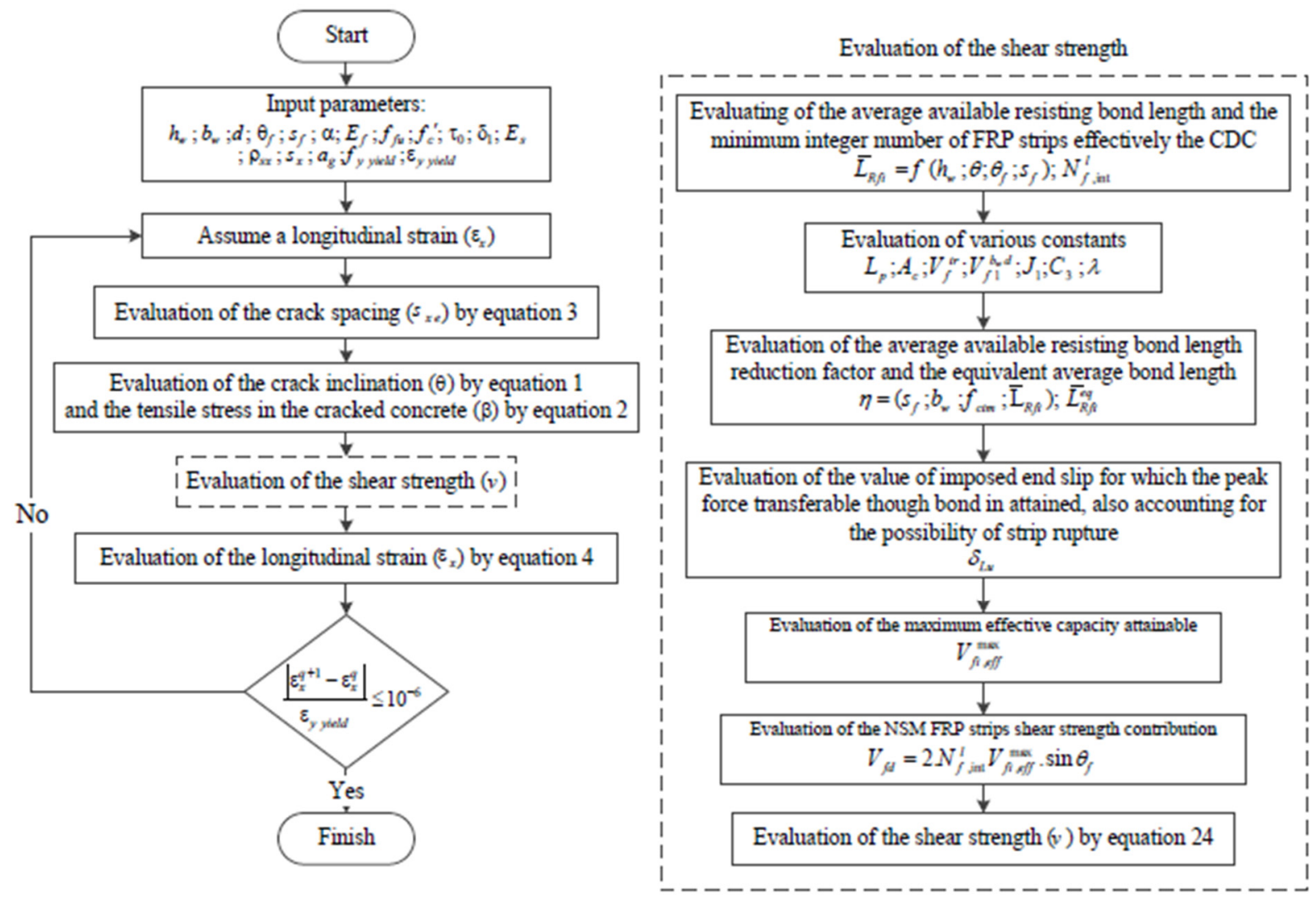

Fig. 4 - Calculation procedure of BSMCFT 


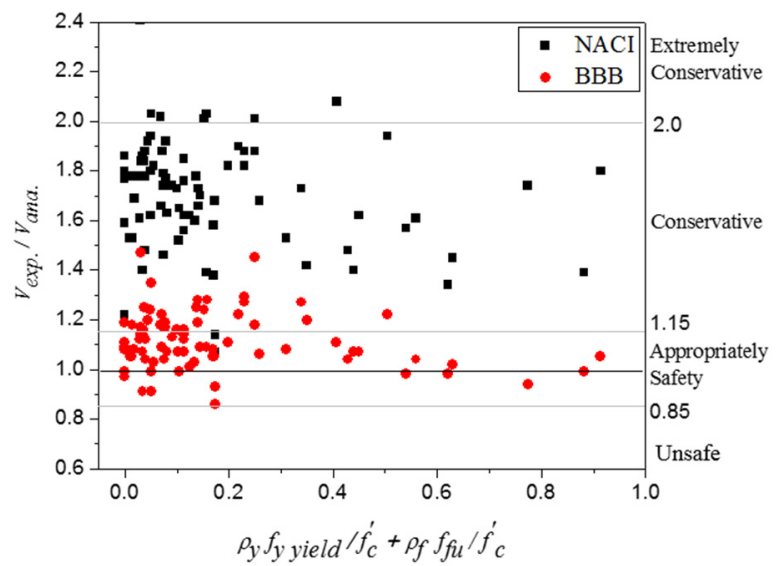

a)

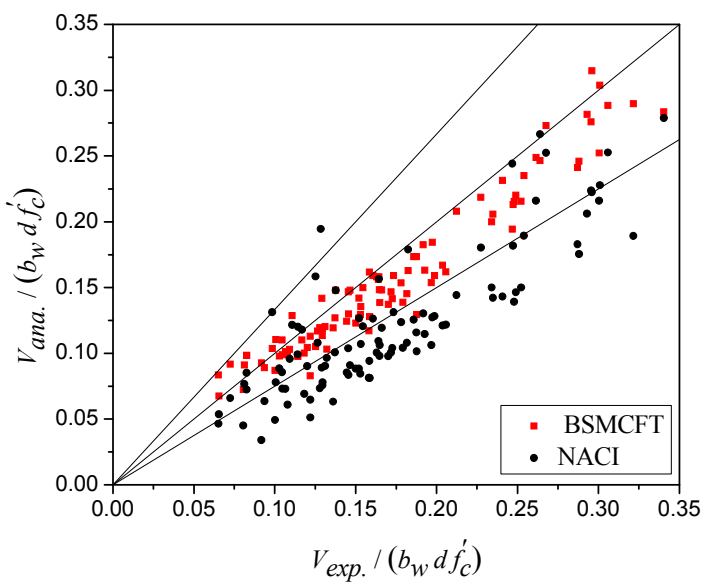

b)

Fig. 5- a) Ratio between experimental and predicted shear resistance; b) Predicted nondimensional failure shear force of the beams, in compression with experimental values. 